\title{
Effectiveness of Mindfulness Training in Enhancing Executive Function and Decreasing Symptoms of Depression and Anxiety in Patients with Multiple Sclerosis (MS)
}

\author{
Mahsa Amiri', Mehdi Rabiei2*, Vahid Donyavi ${ }^{3}$ \\ ${ }^{1}$ Department of Clinical Psychology, Ghazvin Branch, Islamic Azad University, Ghazvin, Iran \\ ${ }^{2}$ Department of Clinical Psychology, Baqiyatallah University of Medical Sciences, Tehran, Iran \\ ${ }^{3}$ Department of Psychiatry, AJA University of Medical Science, Tehran, Iran \\ Email: *Psychology @yahoo.com
}

Received 25 May 2016; accepted 19 July 2016; published 22 July 2016

Copyright (C) 2016 by authors and Scientific Research Publishing Inc.

This work is licensed under the Creative Commons Attribution International License (CC BY).

http://creativecommons.org/licenses/by/4.0/

(c) (i) Open Access

\begin{abstract}
The purpose of the present study was to evaluate the effectiveness of mindfulness training in enhancing executive function and decreasing symptoms of depression and anxiety in multiple sclerosis patients. The population in this study consisted of people with MS who referred to Karaj city MS society in 1394. These people didn't experience medicinal changes during the study period and their expanded disability status score (EDSS) was between 0 and 5.5. 40 of them were randomly selected and placed into two experimental and control groups $(20$ for the experimental and the other for the control group). The treatment of mindfulness training was held in 8 sessions of group training, once a week and for 2 hours. The statistical method of multivariate analysis of covariance was used. The measurement tools were the State-Trait Anxiety Inventory (STAI), the Beck Depression Inventory-II (BDI-II) and the Wisconsin Card Sorting Test (WCST). After all, the results in both groups were compared and evaluated by the use of analysis of covariance. The results showed significant differences in symptoms of anxiety and depression between the two groups $(p<0.05)$; however, no significant difference was observed in executive function between trained and untrained patients $(p>0.05)$. Generally, the results of this research showed positive effects of mindfulness training on reducing anxiety and depression among patients with MS and ineffectiveness of mindfulness training on their executive function. Therefore, considering that there is no certain treatment for MS plus results of this study, the application of mindfulness training can be quite useful to reduce levels of anxiety and depression in patients with MS.
\end{abstract}

*Corresponding author.

How to cite this paper: Amiri, M., Rabiei, M. and Donyavi, V. (2016) Effectiveness of Mindfulness Training in Enhancing Executive Function and Decreasing Symptoms of Depression and Anxiety in Patients with Multiple Sclerosis (MS). Journal of Behavioral and Brain Science, 6, 329-336. http://dx.doi.org/10.4236/jbbs.2016.68032 
Keywords

Mindfulness, Executive Function, Depression, Anxiety, Multiple Sclerosis Patients

\section{Introduction}

Multiple Sclerosis (MS) is an autoimmune disease that causes axonal damage of the Central Nervous System (CNS). Axonal damage is the actual cause of irreversible disabilities in patients with MS [1]. About $48 \%$ of people with MS experience symptoms of anxiety and depression in the first year after the diagnosis [2]. Frederich (2011) showed that $46.4 \%$ of patients with MS suffer from severe stress, 55.4\% from mild anxiety and 19.2\% from severe anxiety. Moreover, the emergence of anxiety and depression symptoms in MS patients causes recurrence of MS symptoms and makes patients' improvement more difficult. Therefore, it can be stated that there are significant relationships between depression, anxiety and MS [3]. In addition to psychological symptoms, impaired executive functioning is included in MS symptoms. There are three domains of executive functions: 1) response inhibition; 2) mental task switching; and 3) and control of working memory representations. In an extensive review, Nigg [4] distinguished between different types of cognitive inhibition. Executive inhibition includes processes of intentional control or response inhibition in relation to long-term goals that can be assessed through Stroop Paradigms. Task switching includes mental flexibility, maintenance ability and set-shifting [5].

For MS patients, many psychological treatments, such as Cognitive-Behavioral Therapy (CBT), have been introduced; however, there are still many shortcomings in this area. Mindfulness-based approaches are among the most recent psychological treatments that have been formed based on spiritual traditions of the East, including meditation and traditional cognitive-behavioral techniques. Kabat-Zinn has defined mindfulness as focusing on the present moment in a purposeful and non-judgmental way. Mindfulness is experience without judgment [6]. Based on the integration of meditation and physical awareness techniques, mindfulness-based approaches are designed to increase automatic awareness of thoughts, feelings and physical sensations. Using mindfulness techniques, automatic responses to different thoughts, feelings and physical sensations can be altered [7].

Mindful people can percept internal and external realities without distortion and have great strength in the face of a wide range of thoughts, emotions and experiences (either pleasant or unpleasant) [8] [9]. Mindful people pay careful attention to their current interpretation of reality which is done by separating their reactions from raw sensory data [10]. Mindfulness techniques have originated from Buddhist meditation exercises that increase awareness beyond thinking. Many techniques and methods have been used to develop mindfulness; however, mindfulness is neither a method nor a set of techniques. Some scholars have defined mindfulness as a way of "being" or "knowing" requiring an understanding of personal feelings [11]. Mind can be realized in two main ways of "doing" and "being". Through mindfulness training, people can learn to think differently (KabatZinn, quoted by [6]).

Mindfulness is positively related to subjective, psychological and mental well-being; whereas, self-awareness is associated with low-levels of psychological well-being [9] [12] [13]. It has been indicated that mindfulness training, as an intervention, is effective in the treatment of both psychological and physical symptoms [14] [15]. Kabat-Zinn and colleagues [16] showed that mindfulness training (i.e. helping people use a combination of relaxation and mindfulness meditation techniques) can be considered as a psychological method to reduce stress. Analyzing the role of mindfulness in emotions and moods, the studies have shown that mindfulness can predict self-regulatory behaviors and positive emotions and enhance well-being through a combination of liveliness and vivid experiences [17]. Mindfulness leads to better quality of life, more enjoyment in life and reduced levels of depression and anger [18]. Studies have also shown that mindfulness has an important role in reducing shortterm and long-term symptoms of low mood [19]. In a study entitled "Distress improves after mindfulness training for progressive MS: A pilot randomized trial”, Bogosian and colleagues [20] showed that the average anxiety score of patients in the experimental group was significantly lower than the average anxiety score of patients in the control group. In another study entitled "Mindfulness-based interventions in multiple sclerosis-a systematic review", Simpson and colleagues [21] showed that these interventions significantly decrease anxiety and depression scores along with MS psychological symptoms of patients with MS.

Given that no study has been conducted to analyze the effectiveness of mindfulness training in improving 
psychological symptoms of patients with MS, the present study can be considered a novel study in this regard. It is important to note that MS leads to psychological damages in addition to sensory and functional damages. Accordingly, the present study was conducted to analyze the effectiveness of mindfulness training in enhancing executive functions and reducing symptoms of anxiety and depression in patients with MS.

\section{Methodology}

The present applied research was conducted on the basis of a mindful-based intervention. The design of this study was pretest-posttest with experimental and control groups. The participants were not aware of their groups.

\subsection{Population}

The population in the present study consisted of all MS patients referred to the Iranian MS Society in November 2015. The participants did not change their medications during the experiment and their Expanded Disability Status Scale (EDSS) scores were in the range of 0 - 5.5 (their scores were determined by the Iranian MS society's physicians). The possible range of EDSS scores is between 0 and 10 (10 indicates death and 0 indicates normal health status [22].

\subsubsection{Sampling Method}

Out of the whole population, 20 volunteers were randomly placed in the experimental group and 20 in the control group. As Miller (2000) indicated, 10 to 15 participants are enough for experimental studies. Fifty patients were recruited (19 females, 21 male), ages ranging from 20 to 40 years (mean $=25.2$; SD $=4.5$ ). Seventeen (85\%) of the participants were single and 3 were married. Their socio-economic status was average or above average. Classification of socio-economic status was based on coding of the subjects income, education and job. Also, they all had some high school diploma and university education. The results of Chi Square tests and Mann-Whitney U-test showed that the differences between the two groups were not significant with regard to gender, education ( $p>0.05$ ). Moreover, the results of an independent samples t-test showed that the differences between the two groups were not significant with regard to age ( $p>0.05)$.

The patients in the experimental group received a mindful-based intervention. All patients included in the study completed the study's questionnaires before the intervention, immediately after the intervention and two months later.

\section{Inclusion criteria}

- No medication change

- $\quad$ EDSS score between 0 and 5.5

- 20 - 40 years of age

- Higher than guidance school education level

- Higher than average anxiety score (state anxiety score: 43 - 53; trait anxiety score: 43 - 52)

- Average depression score (20 - 28)

\section{Exclusion criteria}

- Medication change

- Less than 20 years of age or above 40 years of age

- Lower than guidance school education level

- Lower than average anxiety score (state anxiety score: 32 - 42; trait anxiety score: 32 - 42)

- Lower or higher than average depression score (higher: 29 - 63; lower: 14 - 19)

\subsection{Measurements}

The following measures were completed at the beginning and end of the intervention (that is, 2 months after the start):

The State-Trait Anxiety Inventory (STAI), The Beck Depression Inventory-II (BDI-II) and The Wisconsin Card Sorting Test (WCST) were used in the present study as data collection tools.

\subsubsection{The State-Trait Anxiety Inventory (STAI)}

The STAI [23] is commonly used in clinical settings. It includes separate subscales for measuring state and trait 
anxiety. The STAI consists of two separate 20-item sections (Y-1 \& Y-2) assessing trait anxiety (feelings at the moments) and state anxiety (general feelings). All items are scored on a 4-point Likert scale. Higher scores in 10 items of state anxiety subscale and 11 items of trait anxiety subscale indicate higher levels of anxiety. Therefore, the possible score in each subscale is in the range of 20 - 80. In 1993, Mahram conducted a study to standardize the STAI. He examined reliability coefficient of the STAI in a normative group (600 people); Cronbach's alpha for state anxiety: 0.90; Cronbach's alpha for trait anxiety: 0.90 . To determine validity of the STAI, based on the criterion group sample size (130 anxious people), 130 individuals were randomly selected (with respect to gender and age groups of samples in the criterion group) and then, average scores of state anxiety, trait anxiety and overall anxiety were separately calculated at $95 \%$ and $99 \%$ significance levels; normative indicators (in terms of occupation and education level) were also determined in the mentioned study [24]. Studies have also showed high correlation coefficients between the two subscales of anxiety in the STAI (0.96 \& 0.98 ).

\subsubsection{The Beck Depression Inventory-II (BDI-II)}

Over the past 35 years, the BDI-II has been the most acceptable measures of depression in clinical settings. The BDI-II is the revised version of the BDI-I that measures the severity of depression (during the past two weeks) in adults and adolescents (13 to 18 years). The BDI-I covered only 6 criteria of the 9 depression criteria; therefore, to be consistent with DSM-IV, it was revised and replaced with the BDI-II in 1996. Convergent validity between the BDI-II and the Hamilton Depression Rating Scale (HAM-D) has been reported $r=0.71$. Test-retest reliability of the BDI-II after a one-week interval has been reported 0.93 (Beck, Steer 7 Brown, 1996). Psychometric properties of the BDI-II have been examined on 94 Iranian samples and Cronbach's alpha of 0.91, test-retest reliability of 0.94 and split-half reliability of 0.89 have been reported. In another Iranian study, Cronbach's alphas of 0.87 and test-retest reliability of 0.74 have been calculated for the BDI-II. The BDI-II has 21 items scored on a 4-point Likert scale ranging from 0 to 3; thus, the possible scores are in the range of 0 - 63 [25].

\subsubsection{The Wisconsin Card Sorting Test (WCST)}

The WCST was developed by Grant and Berg (1984) to measure executive functioning (preservation, set shifting and abstract thinking) [26]. This test is one of the most sensitive tests of prefrontal cortex and the dorsolateral frontal lobe functions [27]. The test consists of 64 cards with one to four symbols on each (red triangle, green star, yellow cross and blue circle) and no two cards are similar. The subject is to sort out the cards based on the tester inference. Three factors are considered in the calculation of the WCST results: 1) the number of categories completed showing the overall progress of the examinee; 2) the number of perseverative errors showing that the examinee has used the same rule for his/her choice as the previous choice (this number is the main indicator of cognitive inflexibility and damage in the lateral prefrontal cortex); and 3) the number of total errors (the sum of perseverative and non-perseverative errors). Reliability of the WCST in the assessment of post-traumatic cognitive impairments has been reported more than 0.86 [28]. Naderi (1994) [29] examined reliability of the WCST on Iranian population and reported a test-retest reliability of 0.85 .

\subsection{Procedure}

Initially, in cooperation with the Iranian MS Society in Alborz Province, interested MS patients were invited to participate in this study. Then, based on the study's inclusion criteria, 40 volunteers were randomly selected and divided into two groups of experimental and control.

\subsubsection{Mindfulness Training}

Eight sessions of mindfulness training (two hours once a week) were held in line with the clinical protocol developed by Williams, Segal and Teasdale [6]. Details of the sessions are explained in the following paragraphs.

\section{First session: Autopilot}

Explanation of the first session's objectives; setting general policy with regard to aspects of confidentiality and participants' personal life; asking the participants to form groups of two people and introduce themselves to each other and then to members of other groups; eating raisins; physical verification exercise; homework; discussion and distribution of leaflets

Second session: Facing barriers 
Physical verification exercise; revision of exercises; revision of homework; feeling and thoughts exercise; recording pleasant events; meditation for 1 to 10 minutes in sitting position

\section{Third session: Mindfulness via breathing}

Seeing and hearing exercise; meditation for 30 to 40 minutes; revision of homework; three-minute breathing exercise; walking with mindfulness

\section{Fourth session: Staying in the present moment}

Five minutes of seeing and hearing exercise; meditation for 40 minutes; awareness of breathing, body, voice and thoughts; thought revision exercise; revision exercise; homework

Fifth session: Permission/Presence license

Meditation for 40 minutes in sitting position; revision exercise; homework; breathing exercise; revision of breathing exercise

\section{Sixth session: Thoughts are not real}

Meditation for 40 minutes in sitting position; awareness of breathing and voices; thought revision exercise; revision exercise; homework; getting ready to finish the sessions

\section{Seventh session: Self-care}

Meditation for 40 minutes in sitting position; awareness of breathing, body, voice and thoughts; thought revision exercise; revision exercise; homework; understanding the relationship between activities and mood

Final session: Using new knowledge

Review and conclusion

\subsubsection{Intervention Validity}

All sessions were recorded and their contents were consistent with the applied clinical protocol; therefore, validity of the intervention was confirmed.

\subsection{Data Reduction and Analysis}

First, we conducted descriptive statistics, including distribution of continuous variables. We then calculated patients' satisfaction with treatment. Using the SPSS software, the collected data were analyzed through descriptive statistics (mean and SD) and inferential statistics (Multivariate and Univariate Analysis of Covariance). Effect sizes were computed by using Cohen's $d$.

Treatment refusers and drop-outs

There were no drop-outs in this study. The mean number of sessions that participants attended to was 7; Two participants were absent for 2 sessions because of their final exams. We believe that the reasons for the absence of drop-outs are as follows:

1) The participants were all highly motivated, well-educated and volunteers

2) There was no charge for participation

\section{Ethical Considerations}

In this study, the project's objectives were explained for the population; then, after obtaining the participants' consent forms, they were included in the study. Due to ethical considerations, participants in the control group received the intervention too; but, after the experimental period.

\section{Results}

As shown in Table 1, there were significant differences in both state and trait anxiety between the two groups at a 99\% confidence level. In other words, mindfulness-based interventions (or mindfulness training) could significantly reduce levels of anxiety in patients with MS (Cohen's $d=0.74$ ). Results of univariate ANCOVA for comparing levels of depression between the groups. As shown in Table 1, the results of univariate ANCOVA for comparing levels of depression between the two groups indicated a significant difference at a $99 \%$ confidence level (Cohen's $d=0.68$ ). Accordingly, participants in the experimental group (who had received mindfulness training) had lower depression scores compared to those in the control group. The results of univariate ANCOVA for comparing dimensions of executive function between the two groups indicated no significant difference. In other words, mindfulness training did not significantly affect executive functioning of MS patients. 
Table 1. Results of univariate ANCOVA for comparing levels of anxiety, depression and executive function between the groups.

\begin{tabular}{ccccccc}
\hline Dimensions & Sources & Sum of squares & Degree of freedom & Mean square & F & Sig. \\
\hline \multirow{2}{*}{ State anxiety } & Pretest & 170.18 & 1 & 170.18 & 2.14 & 0.152 \\
& Group & 1140.98 & 1 & 1140.98 & 14.37 & 0.00 \\
Trait anxiety & Pretest & 341.06 & 1 & 341.06 & 5.66 & 0.023 \\
& Group & 1034.06 & 1 & 1034.06 & 17.18 & 0.00 \\
Depression & Pretest & 265.83 & 1 & 365.83 & 5.19 & 0.81 \\
Categories & Group & 759.59 & 1 & 759.59 & 10.78 & 0.00 \\
number & Pretest & 11.43 & 1 & 11.43 & 19.06 & 0.00 \\
Perseverative & Group & 0.08 & 1 & 0.08 & 0.13 & 0.71 \\
error & Pretest & 124.69 & 1 & 124.69 & 8.22 & 0.00 \\
Specific error & Group & 2.79 & 1 & 2.79 & 0.19 & 0.65 \\
\hline
\end{tabular}

\section{Discussion}

The results of univariate ANCOVA for comparing dimensions of executive function between the two groups indicated no statistically significant difference. This finding was inconsistent with results of many other studies including a study conducted by Dennison and colleagues [30]. Executive functions are parts of neuropsychological activities that require a long time to change; therefore, possible positive effects of mindfulness training can only be observed if the training continues for a long time. In the present study, only 8 sessions of mindfulness training were held that might explain the results of this study concerning ineffectiveness of mindfulness training on executive functioning of the examined MS patients.

The results of ANCOVA showed significant differences in anxiety and depression between the two groups of MS patients. Accordingly, MS patients in the experimental group (who had received mindfulness training) had lower anxiety and depression scores compared to those in the control group. These results were in line with results of other studies [20] [21] [31].

Considering that mindfulness-based interventions put an emphasis on the present moment and that MS patients have poor concentration, the present study tried to encourage MS patients to focus on the present moment and try to enjoy the peace resulting from the acceptance of positive and negative thoughts. Through mindfulness training, the patients realized that they were so eager to be in control of their thoughts and feelings. Mindfulness training was a success in the present study as it helped the examined patients accept their disease as a reality. Accordingly, they tried to live in the moment without thinking about their problems. They also could control their negative thoughts and understand the value of their existence regardless of their disease.

There are also limitations in this study, meaning that the results need to be interpreted with some caution. Because of the small sample size, it was not possible to compare mindfulness training to another form of treatment to control for the effect of therapist attention. Among the limitations of the present study, difficulties in obtaining consent forms, difficulties in having access to the participants and data collection can be mentioned. The WCST is a somehow vague test; thus, some patients were not cooperative when completing it and some of them were dissatisfied with the testing process. The other limitation was that some variables that might affect the results (such as socioeconomic status) were not examined in the present study. This study was conducted on MS patients who referred to the Iranian MS Society in the city of Karaj; therefore, generalization of the results to other settings should be done cautiously. In this study, it was not possible to compare the effects of mindfulness training with other types of MS treatments. This paper aimed to describe the aspects of the mindfulness training and treatment of MS. It is possible that an explicit treatment focus on mindfulness could improve the absolute efficacy rates for this disorder. Whilst studies evaluating the efficacy of mindfulness training are in their infancy, the results thus far are promising and merit further large scale investigations. A fascinating and enlightening 
study would be a direct comparison of mindfulness training with CT, CBT, MCT and drug therapy. This would further highlight the differences and similarities between treatment approaches and their putative mechanisms of action in MS.

\section{References}

[1] Hauser, S.L. and Josephson, S.A. (2010) Harrison Neurology in Clinical Medicine. New York, Chicago, San Francisco, Lisbon, London, Madrid, Mexico City, Milan, New Delhi, San Juan, Seoul, Singapore, Sydney, Toronto, 259-269.

[2] Mitchell, A., Benito-Leon, J., Morales Ganzalez, M.J. and Rivera-Navarro, J. (2005) Quality of Life and Its Assessment in Multiple Sclerosis: Integrating Physical and Psychological Components of Wellbeing. The Lancet Neurology, 4, 556-660. http://dx.doi.org/10.1016/S1474-4422(05)70166-6

[3] Buljevac, D., Hop, W.C.J., Reedeker, W., Janssens, A.C.J.W., van der Meche, F.G.A., van Doorn, P.A., et al. (2003) Selfreported Stressful Life Events and Exacerbations in Multiple Sclerosis: Prospective Study. BMJ, 327, 646. http://dx.doi.org/10.1136/bmj.327.7416.646

[4] Nigg, J.T. (2000) On Inhibition/Disinhibition in Developmental Psychopathology: Views from Cognitive and Personality Psychology and a Working Inhibition Taxonomy. Psychological Bulletin, 126, 220-246. http://dx.doi.org/10.1037/0033-2909.126.2.220

[5] Pennington, B.F. and Ozonoff, S. (1996) Executive Functions and Developmental Sychopathology. Journal of Clinical Psychology, 37, 51-58.

[6] Segal, Z.V., Williams, J.M.G. and Teasdale, J.D. (2002) Mindfulness-Based Cognitive Therapy for Depression: A New Approach to Preventing Relapse. Guilford Press, New York.

[7] Ma, S.H. and Teasdale, J.D. (2004) Mindfulness-Based Cognitive Therapy for Depression: Replication and Exploration of Differential Relapse Prevention Effects. Journal of Consulting and Clinical Psychology, 72, 31-40. http://dx.doi.org/10.1037/0022-006X.72.1.31

[8] Ryan, R.M. and Brown, K.W. (2003) Why We Don't Need Self-Esteem: on Fundamental Need, Contingent Love, and Mindfulness. Psychological Inquiry, 14, 27-82.

[9] Brown, K.W., Ryan, R.M. and Creswell, J.D. (2007) Addressing Fundamental Questions about Mindfulness. Psychological Inquiry, 18, 272-281. http://dx.doi.org/10.1080/10478400701703344

[10] Astin, J.A. (1997) Stress Reduction through Mindfulness Meditation. Psychotherapy and Psychosomatics, 66, 97-106. http://dx.doi.org/10.1159/000289116

[11] Siegel, R.D., Germer, C.K. and Olendzki, A. (2008) Mindfulness: What Is It? Where Does It Come From? Clinical Handbook of Mindfulness. Springer, New York.

[12] Falkenstrom, F. (2010) Studying Mindfulness in Experienced Mediators: A Quasi-Experimental Approach. Personality and Individual Differences, 48, 305-310. http://dx.doi.org/10.1016/j.paid.2009.10.022

[13] Brown, K.W. and Kasser, T. (2005) Are Psychological and Ecological Well-Being Compatible? The Role of Values, Mindfulness, and Lifestyle. Social Indicators Research, 74, 349-368. http://dx.doi.org/10.1007/s11205-004-8207-8

[14] Kabat-Zinn, J. (2003) Mindfulness-Based Interventions in Context: Past, Personal, and Future. Clinical Psychology: Science and Practice, 10, 144-156. http://dx.doi.org/10.1093/clipsy.bpg016

[15] Giluk, T.L. (2009) Mindfulness, Big Five Personality, and Affect: A Meta-Analysis. Personality and Individual Differences, 47, 805-811. http://dx.doi.org/10.1016/j.paid.2009.06.026

[16] Kabat-Zinn, J., Massion, A.O., Kristeller, J., Peterson, L.G., Fletcher, K.E., Pbert, L., et al. (1992) Effectiveness of a Meditation-Based Stress Reduction Program in the Treatment of Anxiety Disorders. The American Journal of Psychiatry, 149, 936-943. http://dx.doi.org/10.1176/ajp.149.7.936

[17] Brown, K.W. and Ryan, R.M. (2003) The Benefits of Being Present: Mindfulness and Its Role in Psychological WellBeing. Journal of Personality and Social Psychology, 84, 822-848. http://dx.doi.org/10.1037/0022-3514.84.4.822

[18] Kieviet-Stijnen, A., Visser, A., Garssen, B. and Hudig, W. (2008) Mindfulness-Based Stress Reduction Training for Oncology Patients: Patients’ Appraisal and Changes in Well-Being. Patient Education and Counseling, 72, 436-442. http://dx.doi.org/10.1016/j.pec.2008.05.015

[19] Godfrin, K.A. and van Heeringen, C. (2010) The Effects of Mindfulness-Based Cognitive Therapy on Recurrence of Depressive Episodes, Mental Health and Quality of Life: A Randomized Controlled Study. Behaviour Research and Therapy, 48, 738-746. http://dx.doi.org/10.1016/j.brat.2010.04.006

[20] Bogosian, A., Chadwick, P., Windgassen, S., Norton, S., McCrone, P., Mosweu, I., Silber, E. and Moss-Morris, R. (2015) Distress Improves after Mindfulness Training for Progressive MS: A Pilot Randomised Trial. Multiple Sclerosis Journal, 21, 1184-1194. http://dx.doi.org/10.1177/1352458515576261 
[21] Simpson, R., Mair, R. and Mercer, S. (2015) Mindfulness-Based Interventions for People with Multiple Sclerosis. Multiple Sclerosis Journal, 10, 1177-1190.

[22] Kurtzke, J.F. (1983) Rating Neurologic Impairment in Multiple Sclerosis: An Expanded Disability Status Scale (EDSS). Neurology, 33, 1444-1452. http://dx.doi.org/10.1212/WNL.33.11.1444

[23] Spielberger, C.D., Gorsuch, R.L., Lushene, R., Vagg, P.R. and Jacobs, G.A. (1983) Manual for the State-Trait Anxiety Inventory. Consulting Psychologists Press, Palo Alto.

[24] Grös, D.F., Antony, M.M., Simms, L.J. and McCabe, R.E. (2007) Psychometric Properties of the State-Trait Inventory for Cognitive and Somatic Anxiety (STICSA): Comparison to the State-Trait Anxiety Inventory (STAI). Psychological Assessment, 19, 369-381. http://dx.doi.org/10.1037/1040-3590.19.4.369

[25] Kühner, C., Bürger, C., Keller, F. and Hautzinger, M. (2007) Reliability and Validity of the Revised Beck Depression Inventory (BDI-II). Results from German Samples. Der Nervenarzt, 78, 651-656. http://dx.doi.org/10.1007/s00115-006-2098-7

[26] Cavallaro, R., Cavedini, P., Mistertta, P., et al. (2003) Basal-Corticofrontal Circuits in Schizophrenia and ObsessiveCompulsives Disorder. Biological Psychiatry, 54, 437-443. http://dx.doi.org/10.1016/S0006-3223(02)01814-0

[27] Goldberger, D.P. and Weinberger, D.R. (1998) Probing Prefrontal Function in Schizophrenia with Neuropsychological Paradigms. Schizophrenia Buellton, 14, 179-183. http://dx.doi.org/10.1093/schbul/14.2.179

[28] Lezak, M. (2004) Neuropsychological Assessment. Oxford University Press, Oxford.

[29] Ghadiri, F., Jazayeri, A., Ashayeri, H. and Ghazi Tabatabai, M. (2006) Executive Function Deficits in Schizo-Obsessive Patients. Advances in Cognitive Science, 8, 11-24.

[30] Dennison, L., Moss-Moris, R. and Chalder, T. (2009) A Review of Psychological Correlates of Adjustment in Patients with Multiple Sclerosis. Clinical Psychology Review, 29, 141-153. http://dx.doi.org/10.1016/j.cpr.2008.12.001

[31] Gilbertson, R.M. (2015) Effects of Mindfulness in Motion on Adults with Multiple Sclerosis. Master Thesis, College of Education and Human Service Professions, University of Minnesota, Duluth.

\section{Submit or recommend next manuscript to SCIRP and we will provide best service for you:}

Accepting pre-submission inquiries through Email, Facebook, Linkedin, Twitter, etc A wide selection of journals (inclusive of 9 subjects, more than 200 journals)

Providing a 24-hour high-quality service

User-friendly online submission system

Fair and swift peer-review system

Efficient typesetting and proofreading procedure

Display of the result of downloads and visits, as well as the number of cited articles

Maximum dissemination of your research work

Submit your manuscript at: http://papersubmission.scirp.org/ 